\title{
Endoscopic retrieval of a migrated surgical clip in a choledochojejunal anastomosis using the rendezvous technique
}

It is a rare complication for a surgical clip to migrate into a bile duct $[1,2]$, and removing a migrated surgical clip endoscopically is technically challenging, particularly in patients with surgically altered anatomy. We report here the first successful endoscopic removal of a migrated surgical clip using the rendezvous technique of percutaneous transhepatic biliary drainage (PTBD) and double-balloon endoscope (DBE)-assisted endoscopic retrograde cholangiography (ERC) ( Video 1).

A 35-year-old woman with a history of congenital biliary dilatation who had undergone extrahepatic bile duct resection and choledochojejunostomy 8 months previously was admitted for obstructive jaundice. Computed tomography and magnetic resonance cholangiopancreatography showed intrahepatic biliary dilatation and anastomotic obstruction of the choledochojejunal anastomosis ( Fig. $\mathbf{1} \mathbf{a}, \mathbf{b})$. We attempted ERC assisted by a short-type DBE (El-580BT; Fujifilm, Tokyo, Japan). Insertion to the blind end and discovery of the choledochojejunal anastomosis were successful; however, endoscopic imaging showed obstruction with a migrated surgical clip in the choledochojejunal anastomosis ( $\mathbf{F i g . 1 c}$ ).
It was difficult to gain access into the bile duct beyond the clip, and at this point we gave up the attempt at endoscopic treatment. Four days later, we tried PTBD and succeeded in guiding the tip of a PTBD catheter beyond the clip to the jejunal side of the obstruction. As the patient firmly refused to undergo further surgery, however, we reattempted DBE-as- sisted ERC. The endoscopic catheter successfully accessed the bile duct using the PTBD catheter ( $>$ Fig. 2 ). After dilation using an 8-mm biliary dilation balloon (REN; Kaneka, Osaka, Japan) was successful, the migrated surgical clip was carefully removed with forceps, allowing placement of two endoscopic biliary drainage tubes consisting of 5-Fr plastic stents.

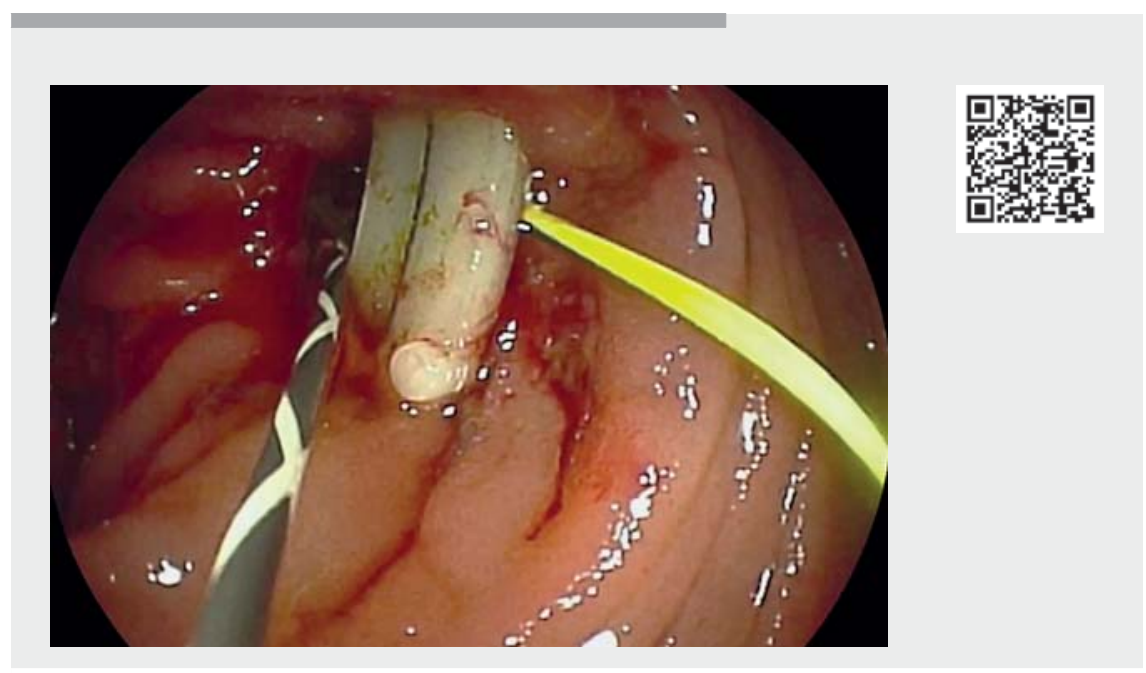

Video 1 Endoscopic retrieval of a migrated surgical clip in a choledochojejunal anastomosis using the rendezvous technique: percutaneous transhepatic bile duct drainage and double-balloon endoscope-assisted endoscopic retrograde cholangiopancreatography.
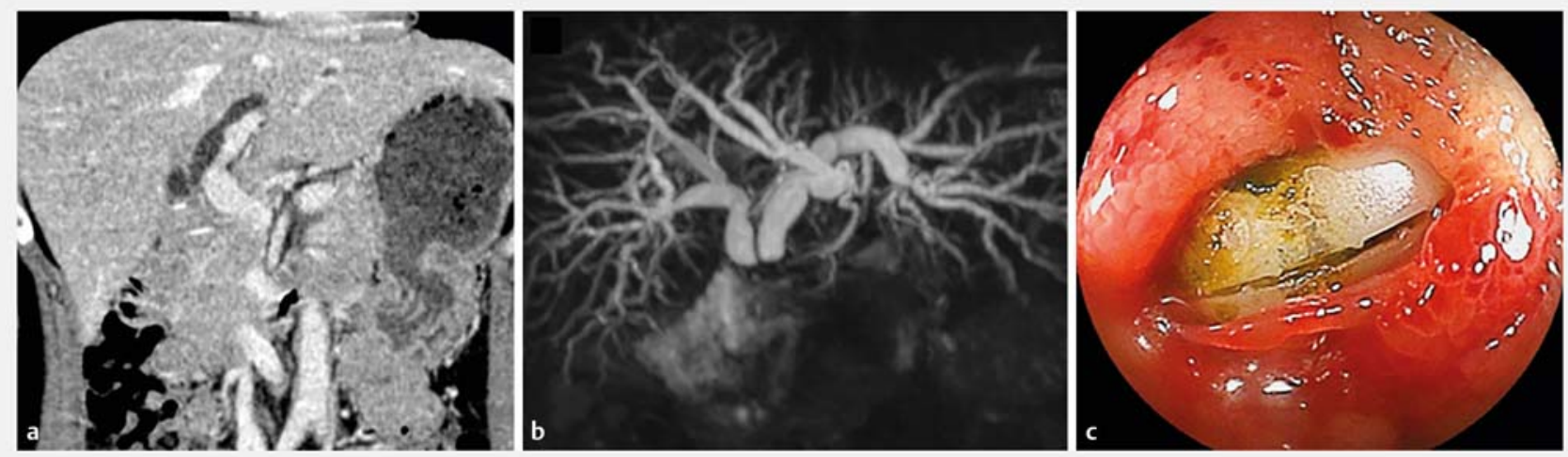

- Fig. 1 Intrahepatic biliary dilation and anastomotic obstruction of a choledochojejunal anastomosis: a computed tomography, b magnetic resonance cholangiopancreatography. c Short-type double-balloon endoscopic imaging showed obstruction due to a migrated surgical clip in the choledochojejunal anastomosis. 

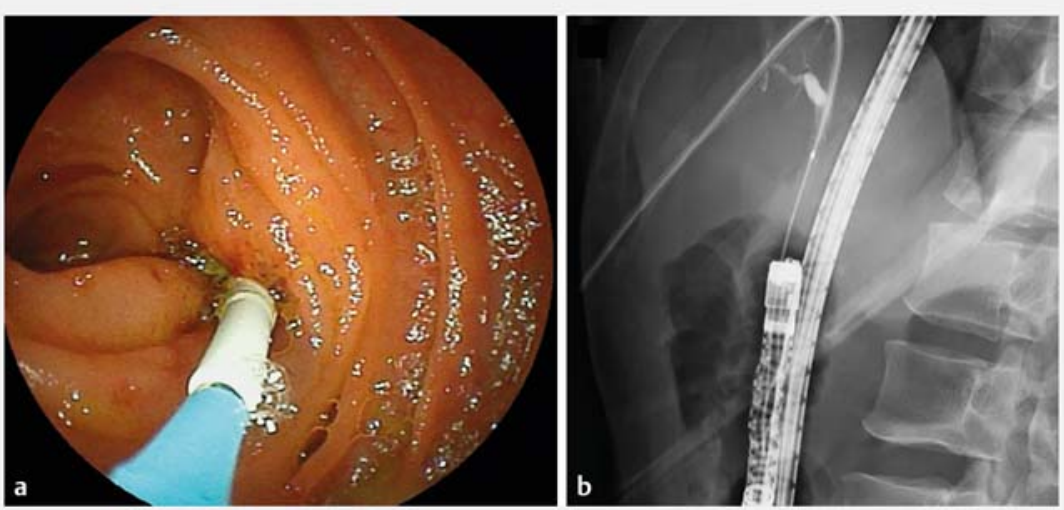

- Fig. 2 a, b Endoscopic catheter successfully accessed the bile duct by means of the percutaneous transhepatic biliary drainage catheter, using the rendezvous technique.

The DBE-assisted ERC-PTBD rendezvous technique has been reported to be effective [3-5]. A combined PTBD procedure which exerts force on the tip of the catheter may also be effective, especially if endoscopic treatment for postoperative mechanical obstruction is unsuccessful.

Endoscopy_UCTN_Code_TTT_1AO_2AL

\section{Competing interests}

The authors declare that they have no conflict of interest.

The authors

Takashi Ito, Masaaki Shimatani, Masataka Masuda, Koh Nakamaru, Toshiyuki Mitsuyama, Makoto Takaoka, Makoto Naganuma

Kansai Medical University, The Third Department of Internal Medicine, Division of Gastroenterology and Hepatology, Hirakata, Japan

\section{Corresponding author}

\section{Masaaki Shimatani, MD, PhD}

The Third Department of Internal Medicine, Division of Gastroenterology and Hepatology, Kansai Medical University, 2-5-1 Shinmachi, Hirakata, Osaka, Japan shimatam@takii.kmu.ac.jp

\section{References}

[1] Chong VH, Chong CF. Biliary complications secondary to post-cholecystectomy clip Surg 2010; 14: 688-696

[2] Daniel S, Oren G, Barch O et al. Cholangitis caused by surgical clip migration into the common bile duct: a rare complication of a daily practice. BMJ Case Rep 2020; 13 : e231201

[3] Mönkemüller K, Popa D, McGuire B et al. Double-balloon enteroscopy-ERCP rendezE334

[4] Bokemeyer A, Müller F, Niesert H et al. Pervous procedures are effective and safe in
[5] Yamauchi H, Kida M, Imaizumi H et al. Innovations and techniques for balloon-enteroscope-assisted endoscopic retrograde cholangiopancreatography in patients with altered gastrointestinal anatomy. World J Gastroenterol 2015; 21: 6460-6469

\section{Bibliography}

Endoscopy 2022; 54: E182-E183

DOI 10.1055/a-1463-2618

ISSN 0013-726X

published online 12.5.2021

(C) 2021. Thieme. All rights reserved.

Georg Thieme Verlag KG, Rüdigerstraße 14,

70469 Stuttgart, Germany

\section{ENDOSCOPY E-VIDEOS}

https://eref.thieme.de/e-videos migration: review of 69 cases. J Gastrointest vous technique. Endoscopy 2013; 45: E333cutaneous-transhepatic-endoscopic rendezpatients with refractory bile duct obstruction. United European Gastroenterol J 2019; 3: 397-404
This section has its own submission website at https://mc.manuscriptcentral.com/e-videos 